\title{
Experimental Investigation and Modelling of Carbonation Process in Cement Materials
}

\author{
Son Tung Pham*
}

Laboratoire de Génie Civil et Génie Mécanique (LGCGM), Department Civil Engineering, National Institute of Applied Sciences of Rennes, INSA-Rennes, 20 Avenue des Buttes de Coësmes, CS 70839, 35708 Rennes Cedex 7, France

\begin{abstract}
Cement mortar and cement paste samples were prepared and subjected to accelerated carbonation test at $20^{\circ} \mathrm{C}$, $65 \%$ humidity relative, $20 \%$ or $50 \%$ concentration of $\mathrm{CO}_{2}$. The carbonation depth was determined using classical phenolphthalein test. The mass fractions of $\mathrm{Ca}(\mathrm{OH})_{2}$ and $\mathrm{CaCO}_{3}$ were calculated from thermogravimetric analysis. We studied different factors that influence the carbonation process such as: concentration of $\mathrm{CO}_{2}$, type of material, surface exposure to $\mathrm{CO}_{2}$, porosity accessible to water, duration of carbonation. Based on the experimental results, a numerical simulation was developed to predict the carbonation depth. This physicochemical and deterministic model relies upon a detailed description of the carbonation mechanism as it takes into account the chemical kinetics, the microstructural and hydrous evolutions induced.
\end{abstract}

Keywords: Carbonation; Thermogravimetric analysis; Modelling; Cement materials.

\section{INTRODUCTION}

The carbonation consists of the reaction of carbon dioxide (CO2) from the atmosphere, which diffuses in gaseous form in the concrete pores and dissolves to form an acid, with the cement paste. The decrease in the $\mathrm{pH}$ leads to the dissolution of cement hydrates, including the portlandite $\mathrm{Ca}(\mathrm{OH}) 2$. When the portlandite is completely consumed, or it is no longer sufficiently accessible, the $\mathrm{pH}$ drops to a value less than 9, allowing the galvanic corrosion of the steel rebar. Carbonation features also a second aspect: the microcrystals of calcium carbonate (CaCO3) which are formed from the hydrates may partially block the pores and thus increase its resistance to the penetration of CO2 [1-4].

Regarding the corrosion caused by carbonation, the easiest way to predict the service life of reinforced concrete structures is to evaluate the duration of the corrosion initiation phase, which corresponds to the time required for the first layer of steel reinforcement to be depassivated by the action of $\mathrm{CO} 2$ [5]. However, neglecting the contribution of the propagation phase of corrosion for the calculation of service life is probably abusive. In fact, this assumption is too safe [6], especially for structures protected from rainwater (tunnels, car parks, etc..). Under these conditions, the steel can be quickly depassivated if the relative humidity is stabilized in a range where the carbonation is optimal (usually for $40 \%<$ relative humidity $<80 \%$ depending on the formulation of concrete [7-10]); in contrast, the corrosion process is limited because the water content of the material is too low for the corrosion to be initiated $[10,11]$. However,

*Address correspondence to this author at the Civil Engineering Department, National Institute of Applied Sciences, France;

Tel.: +33 (0) 6670594 04; E-mail: spham@insa-rennes.fr the assessment of the initiation phase duration is an appropriate method to determine the durability of outdoor structures which are subjected to humidification-drying cycles, because the propagation phase of corrosion is much shorter than the initiation phase $[6,11]$ that is delayed due to the difficulty of $\mathrm{CO} 2$ to diffuse in a high humidity area (relative humidity $>75 \%$ ). The reason is that carbon dioxide in air has a diffusion coefficient of $16 \mathrm{~mm} 2 / \mathrm{s}$, which is 104 times higher than its diffusion coefficient in water that is $0.0016 \mathrm{~mm} 2 / \mathrm{s}[4]$.

The bibliographical review of carbonation modeling has been deeply discussed in detail in the literature. What follows in the rest of the introduction was mainly translated basing on [11]. There are several numerical models that incorporate a physico-chemical approach to reduce the empirical predictions. The model of Saetta et al. [12] is a 1D model to simulate the depth of carbonation, taking into account the water and heat transfer in concrete. The authors consider the kinetic of carbonation of portlandite: the propagation rate increases with the concentration of $\mathrm{CO}_{2}$ and decreases with the degree of progress. The kinetic of carbonation reflects the fact that the carbonation is inhibited during the process because of the restricted availability of $\mathrm{Ca}(\mathrm{OH})_{2}$ crystals. Numerical simulations indicate that the carbonation front is not stiff. However, the model of Saetta et al. can not predict the drop in $\mathrm{pH}$ because the mechanism carbonation is not sufficiently decomposed. Furthermore, the authors fail to include the decrease of the porosity during carbonation process. Saetta et al. [13] subsequently expanded the geometric configurations of the model into two dimensions problem, such as at the corner of a structure. Later, Steffens et al. [14] have completed the model of Saetta et al. by improving the water transfer description. In particular, they introduce an analytical law that connects the water content with the rela- 
tive humidity of the pores. In addition to simulating the natural carbonation of 2D elements exposed to variable environmental conditions, the model is directly used to assess the real risk of corrosion in function of the hydric status of the material. Finally, Saetta and Vitaliani $[6,15]$ have recently conducted an analysis of sensitivity for the model of Saetta et al. taking into account the variability of the input parameters.

The model of Ishida and Maekawa [16] presented a model which simulates the fluctuations $\mathrm{pH}$ using the solution equilibrium between species originating from the dissolution and dissociation of $\mathrm{CO} 2$ (H2CO3, HCO3- and CO32-), calcium ions (Ca2+) and hydroxyl ions (OH-). The only kinetic taken into account by the authors is the precipitation of calcium carbonate CaCO3. While this approach allows obtaining a gradual front of carbonation, it does not seem judicious because in chemistry, it is generally accepted that the precipitation of calcium carbonate is almost immediate in comparison with the dissolution process of portlandite. In addition, Ishida and Maekawa used the law of Saeki et al. [17] linking the reduction of porosity with the degree of carbonation of portlandite, while the carbonation of C-S-H is not taken into account. This description of the carbonation is set up in the code Ducom [18] in order to couple the carbonation with the evolution of hydration and microstructure.

Bary and Sellier [19] proposed a model which coupled the transfer of CO2 in the gas phase with the transfer of liquid water and calcium ions $\mathrm{Ca} 2+$ in aqueous solution. This approach takes into account the carbonation of all hydrated phases: portlandite, C-S-H, ettringite and monosulfoaluminate [20]. The authors introduce a chemical kinetic (in numerical convenience) which corresponds to the precipitation of calcite which is considered almost instantaneous. Otherwise, other chemical reactions (dissolution of portlandite and $\mathrm{C}-\mathrm{S}-\mathrm{H}$ ) are in equilibrium. This virtual absence of chemical kinetics results in a relatively steep carbonation front. With this model, the formation of calcium carbonate leads to large variations in porosity around the carbonation front. More recently, Bary [21] presented a full model incorporating the kinetic effects associated with the formation of a matrix of $\mathrm{CaCO} 3$ around $\mathrm{Ca}(\mathrm{OH}) 2$ crystals, so the dissolution is well slowed down. This way of taking into account the kinetics of dissolution of portlandite crystals was also introduced into the model developed at LCPC [4, 22-24].

Some authors have attempted to consider the presence of cracks which are caused by different forms of shrinkage experienced by the concrete from a young age (chemical, thermal, mechanical and hydric shrinkages). The micro cracks can be taken into account indirectly through the material properties (porosity, coefficient of diffusion, permeability, etc.). The diffusion of $\mathrm{CO} 2$ in the macro cracks can be simulated with a 2D modeling. Isgor and Razaqpur [25] adopted the second solution with finite elements method to describe the carbonation, coupled with water and heat transfers on cracked structures. These authors showed the significant impact of the presence of cracks on carbonation penetration: the carbonation depth can be locally tripled.

Finally, the model of Miragliotta [26] takes into account the hydration and carbonation reactions of $\mathrm{Ca}(\mathrm{OH}) 2$ and $\mathrm{C}$ $\mathrm{S}-\mathrm{H}$, microstructural characteristics and composition (formu- lation and compactness) of the material. This model reflects the temporal evolution of carbonation depth in terms of isothermal diffusion when hydric equilibrium between the material and the surrounding medium is reached. This relationship does not strictly follow the square root of time law, since it takes into account the temporal evolution of porosity during the chemical reactions of hydration and carbonation.

The objective of this work is to develop a model of propagation of $\mathrm{CO} 2$ in cement materials taking into account the evolution of porosity, the chemical rate of carbonation reactions of $\mathrm{Ca}(\mathrm{OH}) 2$ and C-S-H, as well as others factors such as the temperature, the relative humidity and the initial concentration of principal components (portlandite and C-S-H). This model is developed based on the experimental results: thermal analysis was used to determine the mass fraction of portlandite; phenolphthalein test was used to determine the carbonation depth in function of time. Modelling results will be compared with experimental results.

\section{MATERIALS AND METHODS}

\subsection{Standardized Mortar CEM II, CEM I and Cement Paste CEM II}

For this study, we used a normalized mortar prepared with Lafarge cement CEM II/B-M (LL-V) 32.5 R and standardized French sand certified in accordance with norm EN 196-1 and ISO 679:2009. The water/cement and sand/cement ratios were 0.5 and 3 , respectively. We also used a normalized mortar prepared with Lafarge cement CEM I 52,5 N PM-ES-CP2 with exactly the same water/cement and sand/cement ratios. Regarding the cement paste CEM II, the water/cement ratio is 0.5 .

The cements used in this study were fabricated by Lafarge company in accordance with European norm EN 197-1 "Cement - Part 1: Composition, specifications and conformity criteria for common cements”.

At the end of the mixing, the mortar was placed in cylindrical moulds $(\varnothing=40 \mathrm{~mm}, \mathrm{~h}=60 \mathrm{~mm})$ and cubic moulds $(100 \mathrm{~mm} \times 100 \mathrm{~mm} \times 100 \mathrm{~mm})$. The samples were demoulded after 24 hours and then cured for 90 days in a humid chamber $\left(20^{\circ} \mathrm{C}, 100 \%\right.$ relative humidity). The mass fraction of portlandite in the mortars and cement paste will be determined using thermal analysis.

\subsection{Carbonation Test}

Before the carbonation test, the samples were dried at $105^{\circ} \mathrm{C}$ to a constant mass and then stored for 7 days at $20^{\circ} \mathrm{C}$, $65 \%$ relative humidity for homogenization in the internal humidity. To implement the test, the cylindrical samples were protected laterally using an adhesive tape and then subjected to axial diffusion of $\mathrm{CO}_{2}$ in an environmentally controlled chamber at $20^{\circ} \mathrm{C}, 65 \%$ relative humidity and $20 \%$ (or $50 \%)^{C_{2}}$ concentration for a defined time. The carbonation device consists of a climatic chamber Vötsch VP1300 connected to a $\mathrm{CO}_{2}$ tank (Fig. 1). The concentration of $\mathrm{CO}_{2}$ in the chamber is controlled by an automatic $\mathrm{CO}_{2}$ regulator. At the end of the test, some specimens were vertically sawed under water into two parts and the carbonated zone was determined using the classical phenolphthalein test. 


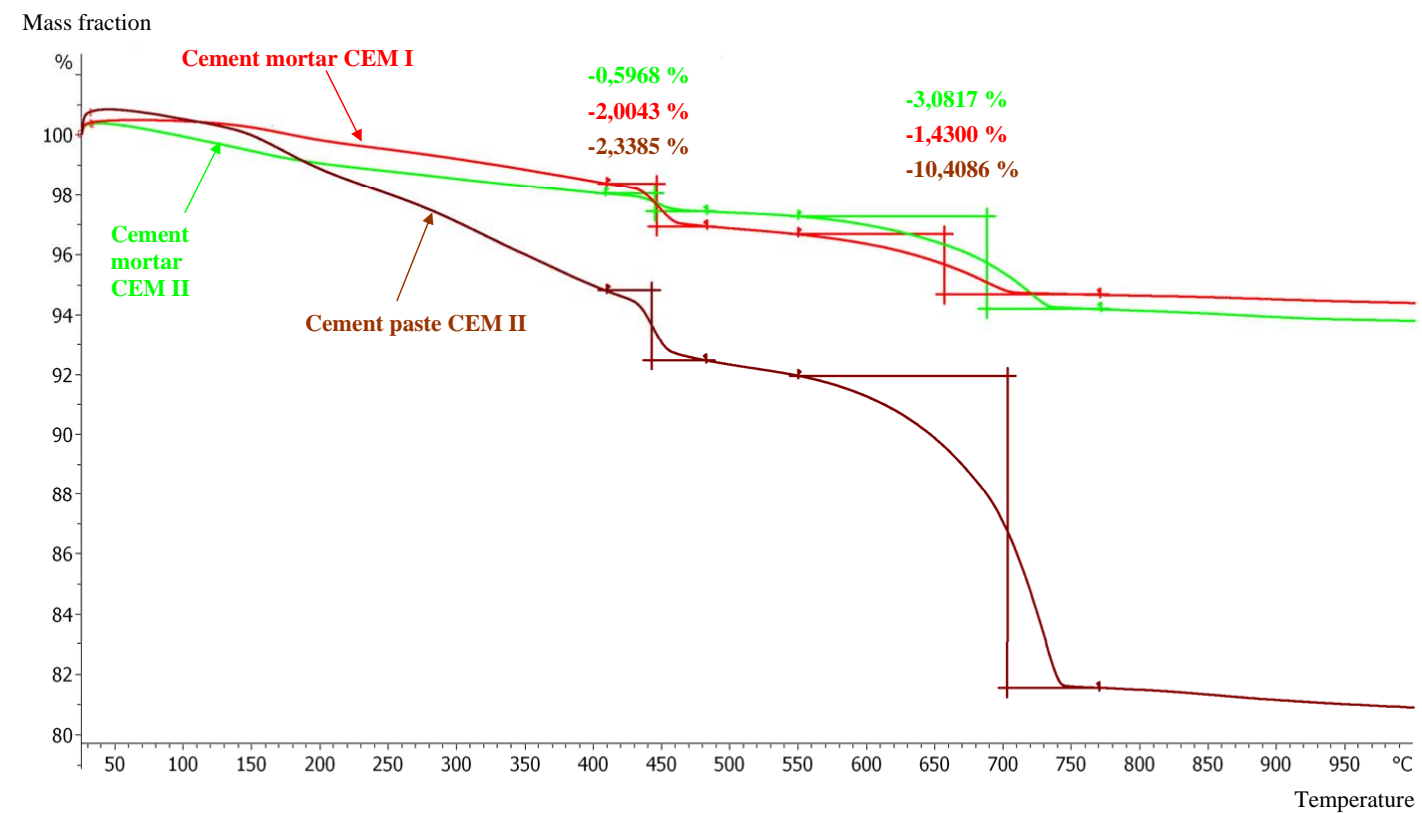

Fig. (1). Accelerated carbonation test device

\subsection{Thermal Analysis}

The thermal analysis was performed using a Mettler Toledo microbalance. The tests were performed under a nitrogen stream in the temperature range from $20^{\circ} \mathrm{C}$ to $1000^{\circ} \mathrm{C}$ with a heating rate of $10^{\circ} \mathrm{C}$ per minute. The analysis of mass loss helped to determine the quantities of portlandite and calcite in the examined sample

\section{RESULTS AND DISCUSSION}

\subsection{Thermal Analysis}

In Fig. (2) we present the results of thermogravimetric analysis (TGA) on cement mortar CEM II, cement mortar
CEM I, and cement paste CEM II. The derivative thermogravimetry (DTG) results are presented in Fig. (3).

In order to calculate the exact mass fraction of cementitious components, the powders were dried at $105^{\circ} \mathrm{C}$ before the thermal analysis until constant mass to exclude free water.

On the derivative thermogravimetric curves (Fig. 3), we observe the corresponding peaks:

(i) The dehydroxylation of calcium silicate hydrate C-S-H between $100^{\circ} \mathrm{C}$ and $300^{\circ} \mathrm{C}$ [4]. In this temperature range, there is also a vaporization of free water, bound water, and decomposition of etringite. As the powder is dried at $105^{\circ} \mathrm{C}$, most of free and bound water has been removed.

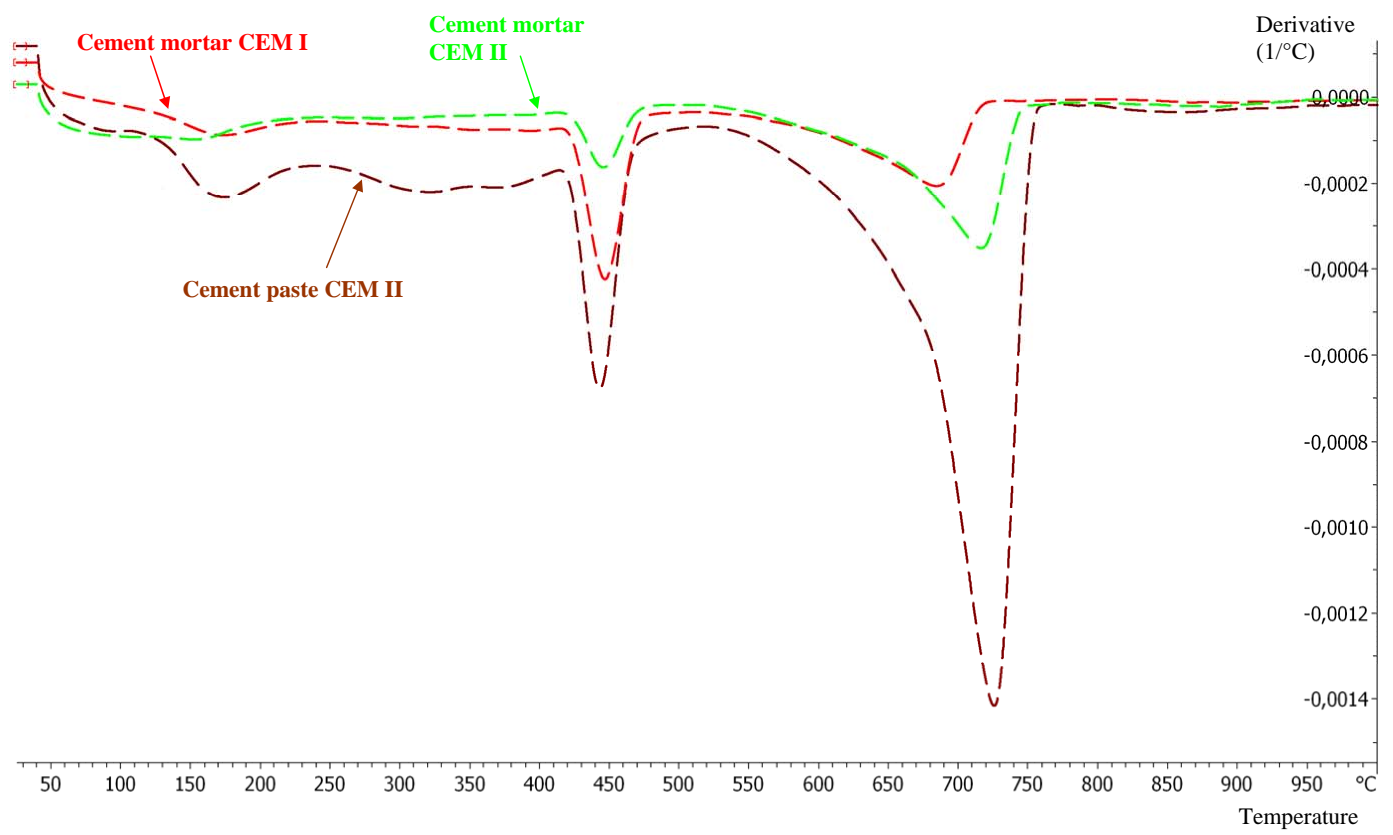

Fig. (2). Thermogravimetric analysis curves. 


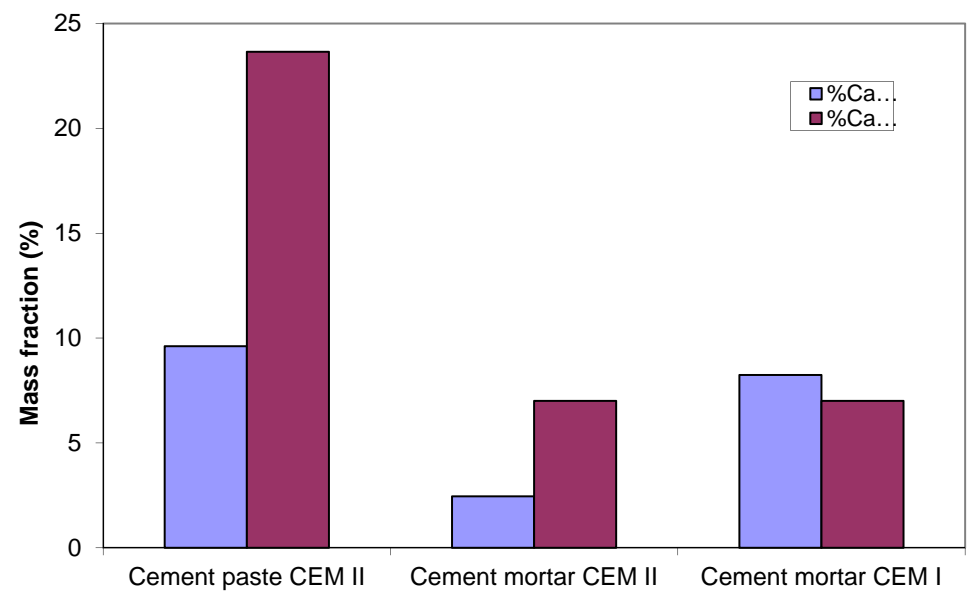

Fig. (3). Derivative thermogravimetry analysis.

The result can provide information about the amount of $\mathrm{C}-\mathrm{S}-\mathrm{H}$. We observe that the cement paste has a very high amount of C-S-H.

(ii) The dehydroxylation of portlandite between $400^{\circ} \mathrm{C}$ and $550^{\circ} \mathrm{C}$ [4]. The result shows that the quantity of $\mathrm{Ca}(\mathrm{OH})_{2}$ contained in cement paste is the highest, followed by cement mortar CEM I.

(iii) The decomposition of calcium carbonate $\mathrm{CaCO}_{3}$ at around $700^{\circ} \mathrm{C}$ [4]. The result shows that the quantity of $\mathrm{CaCO}_{3}$ contained in cement paste is the highest, followed by cement mortar CEM II.

We seek to determine the mass fractions of portlandite and calcium carbonate as follows.

The decomposition of portlandite:

$$
\mathrm{Ca}(\mathrm{OH})_{2}=\mathrm{CaO}+\mathrm{H}_{2} \mathrm{O}
$$

$1 \mathrm{~mol} 1 \mathrm{~mol} 1 \mathrm{~mol}$

\section{$74 \mathrm{~g} \quad 56 \mathrm{~g} \quad 18 \mathrm{~g}$}

$\% \mathrm{H}_{2} \mathrm{O}$ is the percentage of mass loss when $\mathrm{H}_{2} 0$ evaporates; we deduce the mass fraction of portlandite:

$\% \mathrm{Ca}(\mathrm{OH})_{2}=\% \mathrm{H}_{2} \mathrm{O} \cdot \frac{74}{18}$

The decomposition of calcium carbonate:

$$
\mathrm{CaCO}_{3}=\mathrm{CaO}+\mathrm{CO}_{2}
$$

$1 \mathrm{~mol} 1 \mathrm{~mol} 1 \mathrm{~mol}$
$100 \mathrm{~g} 56 \mathrm{~g} 44 \mathrm{~g}$

$\% \mathrm{CO}_{2}$ is the percentage of mass loss when $\mathrm{CO}_{2}$ evaporates; we deduce the mass fraction of calcium carbonate:

$$
\% \mathrm{CaCO}_{3}=\% \mathrm{CO}_{2} \cdot \frac{100}{44}
$$

We present in Fig. (4) the mass fractions of portlandite and calcium carbonate. As C-S-H and $\mathrm{Ca}(\mathrm{OH})_{2}$ react with $\mathrm{CO}_{2}$, the mass fractions of these components in the material influence the propagation rate of $\mathrm{CO}_{2}$. At first sight, we can predict that the CEM I mortar resists to the attack of $\mathrm{CO}_{2}$ better than the CEM II mortar, while the cement paste is the most resistant. However, the spread of $\mathrm{CO}_{2}$ is also influenced by another important factor which is the porosity.

\subsection{Porosity Accessible to Water}

The porosity accessible to water was measured using hydrostatic weighing [27]. This technique does not provide the pore size distribution but the total open porosity including micro, meso and macro pores. This information is critical to the carbonation process because the carbon dioxide diffusion in cementitious matrix is only possible through the open connected porosity. The results are presented in the Table $\mathbf{1}$. The cement paste has the highest porosity, followed by the CEM II mortar. In combination with the results of mass fraction of portlandite in Fig. (4), it reveals that no relation between the total porosity and the amount of $\mathrm{Ca}(\mathrm{OH})_{2}$ can be established. Although the cement paste CEM I has the highest amount of $\mathrm{Ca}(\mathrm{OH})_{2}$, its porosity is the lowest. Otherwise,

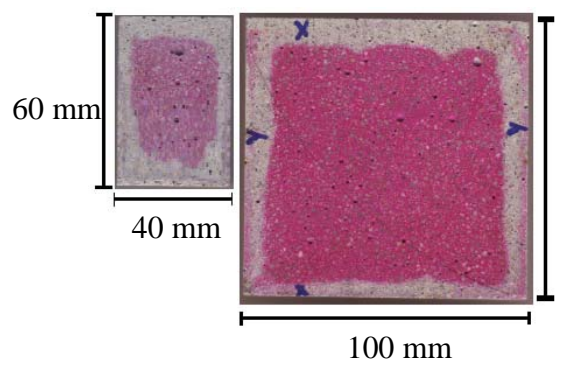

7 days of accelerated carbonation

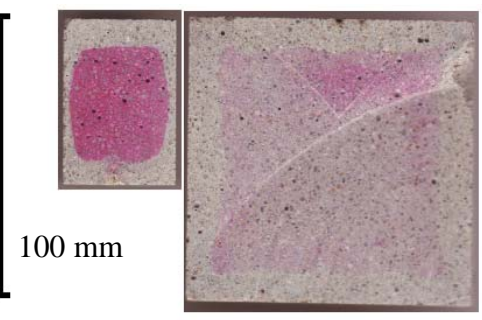

14 days of accelerated carbonation

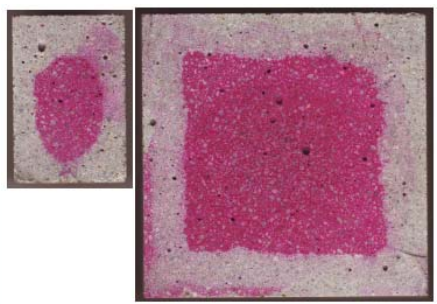

32 days of accelerated carbonation

Fig. (4). Mass fractions of portlandite and calcium carbonate in cement materials. 
Table 1. Porosity Accessible to Water

\begin{tabular}{|c|c|}
\hline Type of Material & Porosity Accessible to Water (\%) \\
\hline \hline Cement paste CEM II & 41,5 \\
\hline Cement mortar CEM II & 18,7 \\
\hline Cement mortar CEM I & 16,3 \\
\hline
\end{tabular}

the cement mortar CEM I has higher porosity and higher amount of $\mathrm{Ca}(\mathrm{OH})_{2}$ than the cement mortar CEM II. So the mass fraction of $\mathrm{Ca}(\mathrm{OH})_{2}$ is not the principal factor influencing the porosity.

\subsection{Influence of the Exposed Surface to $\mathrm{CO}_{2}$}

To study the influence of the surface exposed to CO2, we also used cubic samples (100 mm x $100 \mathrm{~mm}$ x $100 \mathrm{~mm})$ of CEM II cement mortar. These cube samples followed the same treatment as the cylindrical samples. Fig. (5) presents the observations after spraying phenolphthalein on fresh surfaces of the samples subjected to accelerated carbonation at $20 \%$ CO2 concentration. The carbonation depth was measured along the axis $\mathrm{x}$ which is the vertical axis during the preparation of samples. Although the cylindrical samples were protected laterally in order to execute an axial carbonation, as a very active gas, the $\mathrm{CO} 2$ still penetrated from the sides as shown in Fig. (5). The carbonation depth was thus measured mostly in the middle of the sample in order to eliminate the effects of two-dimension carbonation. Moreover, the bottom of the sample is denser than the top of the sample due to the segregation of aggregates during preparation of cement mortar, which results in a more important carbonation depth at the top than at the bottom of the sample. The carbonation depth value is therefore the average of the top and bottom ones. In Fig. (6), we see that carbonation depths for $20 \% \mathrm{CO} 2,20^{\circ} \mathrm{C}$ and $65 \%$ relative humidity are almost the same on the cubic and cylindrical samples.

In the case of an axial carbonation, the surface exposure to $\mathrm{CO} 2$ of a cylindrical sample $(\varnothing=40 \mathrm{~mm}, \mathrm{~h}=60 \mathrm{~mm})$ is about $12.57 \mathrm{~cm} 2$, while the one of a cubic sample (100 mm x $100 \mathrm{~mm} \times 100 \mathrm{~mm})$ is $100 \mathrm{~cm} 2$. Although the two surface exposures values are very different, the carbonation depths are the same for both types of sample. Hence, we can conclude that the surface exposure does not play a significant role. We can therefore assume that the progress direction of carbonation front is perpendicular to the surface exposure. In other words, $\mathrm{CO} 2$ diffusion is perpendicular to the exposed surface of the sample to CO2. If the CO2 also spreads in others directions, the carbonation depth of cubic samples must be much different than the one of cylindrical sample. This observation will be used for developing the carbonation model where we take into account the unidirectional axial propagation of $\mathrm{CO} 2$ in the cement matrix.

\subsection{Influence of the Carbonation Duration}

The carbonation depth for cylindrical samples from Fig. (6) is now presented in function of the square root of the

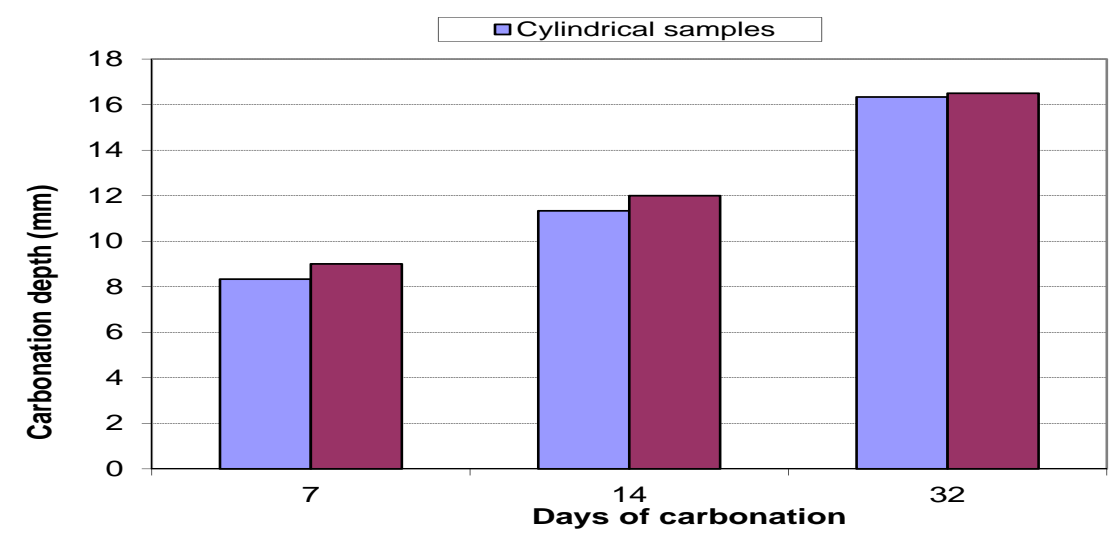

Fig. (5). Revelation of carbonation using phenolphthalein indicator for different duration of carbonation (7 days, 14 days and 32 days). The carbonation depth was measured along the axis $\mathrm{x}$ which is the vertical axis during the preparation of specimens.

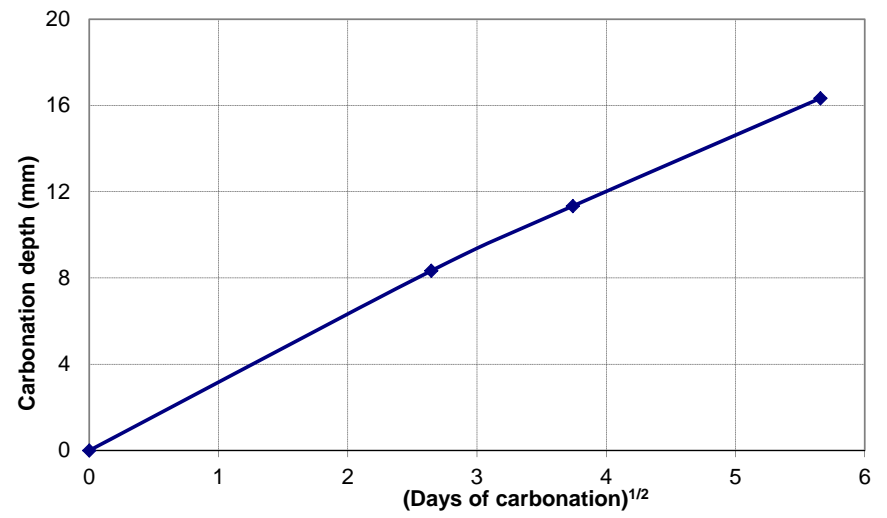

Fig. (6). Influence of surface exposure to $\mathrm{CO}_{2}$ on carbonation depth. 


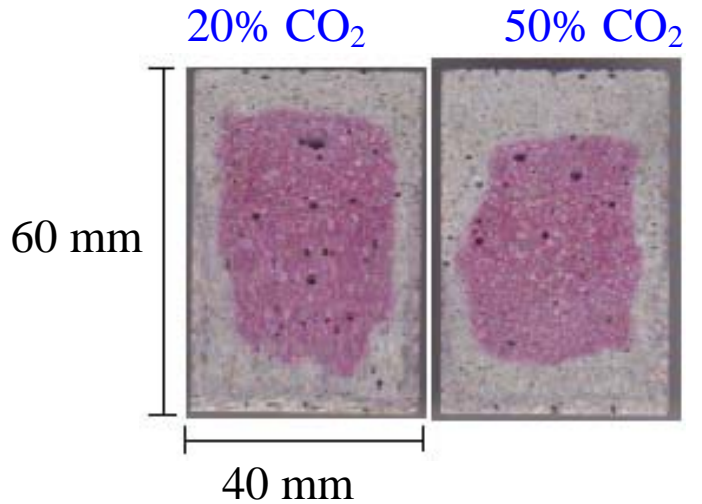

Fig. (7). Carbonation depth of cement mortar CEM II subjected to accelerated carbonation at $20^{\circ} \mathrm{C}, 65 \%$ relative humidity and $20 \%$ concentration of $\mathrm{CO}_{2}$.

duration of carbonation. We observe in Fig. (7) a linear relation between the two values. This result is coherent with the prediction of carbonation depth in literature: $\mathrm{x}=\mathrm{A} \cdot \sqrt{\mathrm{t}}$ [28], where $\mathrm{A}$ is a constant taking into account both the composition of the cement material (water/cement ratio, type of binder,...) and the environmental conditions (relative humidity, temperature, pressure,...). This formula is a general form of experimental modeling of carbonation. The main advantage of the experimental modeling is the simple utilization while omitting many real phenomena that influence the carbonation process such as the changes in porosity, in mass fraction of components, and the non raid frontier of carbonation.

\subsection{Influence of the Concentration of $\mathrm{CO}_{2}$}

Fig. (8) presents the observations after spraying phenolphthalein on fresh surfaces of cement mortar CEM II after 7 days exposure to accelerated carbonation at $20 \% \mathrm{CO} 2$ and $50 \%$ CO2 concentration. From the results presented in Table 2 , we can see clearly that the carbonation depth is more important when the CO2 concentration is $50 \%$. The concentration of $\mathrm{CO} 2$ is therefore a significant factor in carbonation process.
Table 2. Carbonation Depth of Cement Mortar CEM II After 7 Days at Different Concentrations of $\mathrm{CO}_{2}$

\begin{tabular}{|c|c|}
\hline Concentration of $\mathbf{C O}_{2}$ & Carbonation Depth (mm) \\
\hline \hline $20 \%$ & 8,3 \\
\hline $50 \%$ & 13 \\
\hline
\end{tabular}

\subsection{Carbonation Depth for Different Types of Materials}

We present in Table 3 the carbonation depth after 7 days exposure to $20 \% \mathrm{CO}_{2}$. The results show that the depth of carbonation is the highest for the cement paste, followed by mortar CEM I. The result shows that the porosity has a great influence on the propagation of carbonation. Although the cement paste has the greatest amount of $\mathrm{Ca}(\mathrm{OH})_{2}$ and C-S-H, it is the most vulnerable to the attack of $\mathrm{CO}_{2}$ due to its high porosity.

The porosity of CEM I mortar is smaller than that of the CEM II mortar. In addition, CEM I mortar has a quantity of $\mathrm{Ca}(\mathrm{OH})_{2}$ greater than CEM II mortar. For these reasons, the CEM I mortar has a carbonation depth less important than the CEM II mortar.

\subsection{Modelling of Carbonation in Cementitious Materials}

\subsubsection{Basic Equations - Boundary and Initial Conditions}

The carbonation of portlandite:

$\mathrm{CO}_{2}+\mathrm{Ca}(\mathrm{OH})_{2}=\mathrm{CaCO}_{3}+\mathrm{H}_{2} \mathrm{O}$

The carbonation of C-S-H:

$\mathrm{C}_{\mathrm{x}} \mathrm{S}_{\mathrm{y}} \mathrm{H}_{\mathrm{z}}+\mathrm{xH}_{2} \mathrm{CO}_{3}=\mathrm{xCaCO}+\mathrm{ySiO} \cdot \mathrm{tH}_{2} \mathrm{O}+(\mathrm{x}-\mathrm{t}+\mathrm{z}) \mathrm{H}_{2} \mathrm{O}$

Chemical kinetic of the C-S-H [4]:

$\xi_{C S H}^{0}=-\frac{\partial n_{C S H}}{\partial t}=\phi S \frac{K_{H}}{\tau_{C S H}}\left[\mathrm{CO}_{2}\right]$

We suppose that the C-S-H formula is $\mathrm{C}_{3} \mathrm{~S}_{2} \mathrm{H}_{3}$ which is the most common form, so we have:

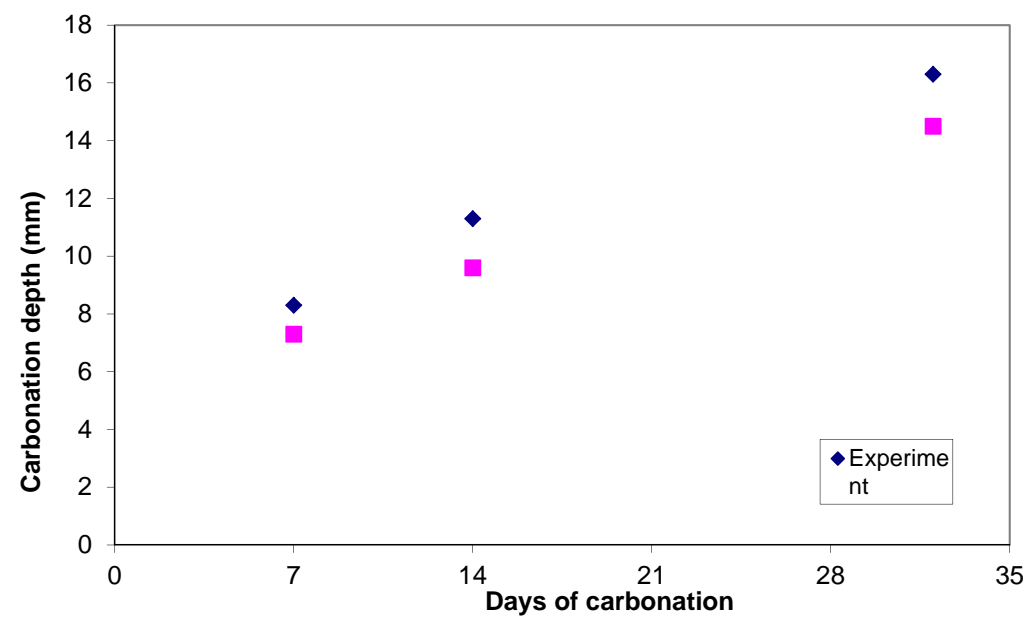

Fig. (8). Revelation of carbonation in cement mortar CEM II after 7 days at $20 \% \mathrm{CO}_{2}$ (left) and $50 \% \mathrm{CO}_{2}$ (right). 
Table 3. Carbonation Depth of Different Materials After 7 Days of Carbonation at $20^{\circ} \mathrm{C}, 65 \%$ Relative Humidity and $20 \%$ Concentration of $\mathrm{CO}_{2}$

\begin{tabular}{|c|c|}
\hline Type of material & Carbonation depth $(\mathbf{m m})$ \\
\hline \hline Cement paste CEM II & 10 \\
\hline Cement mortar CEM II & 8,3 \\
\hline Cement mortar CEM I & 5 \\
\hline
\end{tabular}

$-\frac{\partial n_{C S H}}{\partial t}=\frac{\partial n_{C a C O_{3}}^{C S H}}{3 \partial t}=\phi S \frac{K_{H}}{\tau_{C S H}}\left[\mathrm{CO}_{2}\right]$

where:

$\tau_{C S H} \approx 2800 s$ (Characteristic time of the carbonation reaction of C-S-H obtained by calibration with experimental results)

$\mathrm{K}_{\mathrm{H}}$ : Henry constant

$\mathrm{K}_{\mathrm{H}}=\mathrm{RTH}_{0}$

$\mathrm{H}_{0}$ : Henry constant for pure water

$\phi$ : Porosity accessible to water

S: saturation level of material

$n_{C S H}$ : Number of moles of C-S-H

$\partial n_{\mathrm{CaCO}_{3}}^{\mathrm{CSH}}$ : Number of moles of $\mathrm{CaCO}_{3}$ produced by the carbonation of C-S-H

Chemical kinetic of the portlandite [4]:

$\xi_{\text {portlandite }}^{0}=\frac{\partial n_{\mathrm{CaCO}_{3}}}{\partial t}=\phi S \frac{\left(C_{l}-C_{l}^{e q}\right)}{\tau_{\text {portlandite }}}=\frac{\phi S k}{\tau_{\text {portlandite }}}\left[\mathrm{CO}_{2}\right]$

where:

$C_{l}^{e q}$ : Concentration of $\mathrm{CO}_{2}$ solution in equilibrium state

$C_{l}$ : Total concentration of $\mathrm{H}_{2} \mathrm{CO}_{3}, \mathrm{HCO}_{3}{ }^{-}$, and $\mathrm{CO}_{3}{ }^{2-}$.

$\partial n_{\mathrm{CaCO}_{3}}$ : Number of moles of $\mathrm{CaCO}_{3}$ produced by the carbonation of portlandite.

Conservation of element Carbone [4]:

$\frac{\partial n_{C}}{\partial t}=-\operatorname{div}\left(W_{C}\right)$

where $\mathrm{W}_{\mathrm{c}}$ is the molar flux of element $\mathrm{C}$

with $n_{C}=\phi(1-S)\left[\mathrm{CO}_{2}\right]+\phi S C_{l}+n_{\mathrm{CaCO}_{3}}$

and $W_{C}=W_{C O}$ : the diffusion coefficient of $\mathrm{CO}_{2}\left(\mathrm{D}_{\mathrm{CO} 2}\right)$ in the gaseous phase is $10^{4}$ times greater than in the liquid phase, so we can omit the diffusion of $\mathrm{CO}_{2}$ in the liquid phase.

$W_{\mathrm{CO}_{2}}=-D_{\mathrm{CO}_{2}}(\phi, S) \operatorname{grad}\left[\mathrm{CO}_{2}\right]$

For a unidirectional problem: $x \in[0,+\infty]$, the principal equation to be solved is:

$\phi(1-S+k S) \frac{\partial\left[\mathrm{CO}_{2}\right]}{\partial t}+\frac{\partial n_{\mathrm{CaCO}_{3}}}{\partial t}=D_{\mathrm{CO}_{2}} \frac{\partial^{2}\left[\mathrm{CO}_{2}\right]}{\partial x^{2}}$
With conditions on the concentration of $\mathrm{CaCO}_{3}$ :

(i) $\frac{\partial n_{\mathrm{CaCO}_{3}}}{\partial t}=\frac{\phi S k}{\tau_{\text {portlandite }}}\left[\mathrm{CO}_{2}\right]+\frac{3 \phi S K_{H}}{\tau_{\mathrm{CSH}}}\left[\mathrm{CO}_{2}\right]=\phi S\left[\mathrm{CO}_{2}\right]\left(\frac{k}{\tau_{\text {portlandite }}}+\frac{3 K_{H}}{\tau_{C S H}}\right)$

if $n_{\mathrm{CaCO}_{3}}<n_{\mathrm{Ca}(\mathrm{OH})_{2}}^{0}+3 n_{\mathrm{CSH}}^{0}$

(ii) $\frac{\partial n_{\mathrm{CaCO}_{3}}}{\partial t}=0$ if $n_{\mathrm{CaCO}_{3}}=n_{\mathrm{Ca}(\mathrm{OH})_{2}}^{0}+3 n_{\mathrm{CSH}}^{0}$

For a better resolution, we call that:

$$
\begin{aligned}
& u=\left[\mathrm{CO}_{2}\right] \\
& A=\frac{\partial n_{\mathrm{CaCO}_{3}}}{\partial t} \\
& B=\phi(1-S+k S) \\
& C=D_{\mathrm{CO}_{2}} \\
& D=\phi S\left(\frac{k}{\tau_{\text {portlandite }}}+\frac{3 K_{H}}{\tau_{\mathrm{CSH}}}\right)
\end{aligned}
$$

So we have: $\mathrm{A}=\mathrm{Du}$ if $n_{\mathrm{CaCO}_{3}}<n_{\mathrm{Ca}(\mathrm{OH})_{2}}^{0}+3 n_{\mathrm{CSH}}^{0}$ and $\mathrm{A}=$ 0 if $n_{\mathrm{CaCO}_{3}}=n_{\mathrm{Ca}(\mathrm{OH})_{2}}^{0}+3 n_{\mathrm{CSH}}^{0}$

The principal equation becomes:

(*) $B \frac{\partial u}{\partial t}+D u=C \frac{\partial^{2} u}{\partial x^{2}}$ if $n_{\mathrm{CaCO}_{3}}<n_{\mathrm{Ca}(\mathrm{OH})_{2}}^{0}+3 n_{\mathrm{CSH}}^{0}$

$(* *) B \frac{\partial u}{\partial t}+0=C \frac{\partial^{2} u}{\partial x^{2}}$ if $n_{\mathrm{CaCO}_{3}}=n_{\mathrm{Ca}(\mathrm{OH})_{2}}^{0}+3 n_{\mathrm{CSH}}^{0}$

Boundary and initial conditions:

$\left[\mathrm{CO}_{2}\right](t=0, \forall x \geq 0)=0$

$n_{\mathrm{Ca}(\mathrm{OH})_{2}}(t=0, \forall x \geq 0)=n_{\mathrm{Ca}(\mathrm{OH})_{2}}^{0}$

$n_{C S H}(t=0, \forall x \geq 0)=n_{C S H}^{0}$

$n_{\mathrm{CaCO}_{3}}(t=0, \forall x \geq 0)=n_{\mathrm{CaCO}_{3}}^{0}$

$\left[\mathrm{CO}_{2}\right](\forall t>0, x=0)=\left[\mathrm{CO}_{2}\right]_{0}$

\subsubsection{Resolution by Finite Difference Method}

$i$ is the index of $x$ (space)

$\mathrm{j}$ is the index of $\mathrm{t}$ (time)

$\frac{\partial^{2} u}{\partial x^{2}}\left(x_{i}, t_{j}\right)=\frac{u_{i+1}^{j}-2 u_{i}^{j}+u_{i-1}^{j}}{(\Delta x)^{2}}$

$\frac{\partial u}{\partial t}\left(x_{i}, t_{j}\right)=\frac{u_{i}^{j+1}-u_{i}^{j}}{\Delta t}$

The principal equation (22) becomes:

$B \frac{u_{i}^{j+1}-u_{i}^{j}}{\Delta t}+D u_{j}^{i}=C \frac{u_{i+1}^{j}-2 u_{i}^{j}+u_{i-1}^{j}}{(\Delta x)^{2}}$

After some developments, we finally have: 
$u_{j}^{i+1}=u_{i}^{j}\left(1-\frac{D}{B} \Delta t\right)+\frac{C}{B} \frac{\Delta t}{(\Delta x)^{2}}\left(u_{i+1}^{j}-2 u_{i}^{j}+u_{i-1}^{j}\right)$

In order to solve this differential equation, we used MATLAB to encode the program.

\subsubsection{Comparison Between Experimental Values and Si- mulated Values}

\section{a) INFLUENCE of Duration of Carbonation:}

The experimental and modelling results of carbonation depth in function of time of cement mortar CEM II are presented in Fig. (9). We observe that the results are close enough to justify the validation of the program. We also observe that the modelling values are slightly smaller than the experimental values. There are some reasons for this observation. In reality, the $\mathrm{CaCO}_{3}$ crystals formed from the carbonation of portlandite cover the portlandite crystals. This process decreases the accessibility of the $\mathrm{CO}_{2}$ to react with the portlandite, thus slow down progressively the carbonation rate. In the program, this decrease in the carbonation rate is much more abrupt. Furthermore, the modelling considers that the total quantity of $\mathrm{Ca}(\mathrm{OH})_{2}$ and C-S-H is carbonated, while in reality these components may still remain a small part after carbonation.

\section{b) Influence of the Concentration of $\mathrm{CO}_{2}$}

We present in Fig. (10) the results of cement mortar CEM II after 7 days of carbonation at $20^{\circ} \mathrm{C}, 65 \%$ relative humidity, and for different concentrations of $\mathrm{CO}_{2}$. We can clearly that the higher the concentration of $\mathrm{CO}_{2}$ is, the higher the carbonation depth is. Here again we observe that the modelling values are slightly smaller than the experimental values.

\section{c) Carbonation Depth for Different Type of Material}

In Fig. (11) we present the carbonation depth after 7 days of carbonation at $20^{\circ} \mathrm{C}, 65 \%$ relative humidity, $20 \%$ concentration of $\mathrm{CO}_{2}$. The most influential factor here is the porosity accessible to water, which determines the carbonation depth. The modelling and experimental results show that the higher the porosity is (Table $\mathbf{1}$ ), the higher the carbonation depth is. and the temperature), it will be required to address a probabilistic approach.

\section{CONCLUSIONS}

In this paper, the development of a deterministic model of carbonation was described. The model requires a description of chemical reaction kinetics, including the determination of a characteristic time of the carbonation reaction

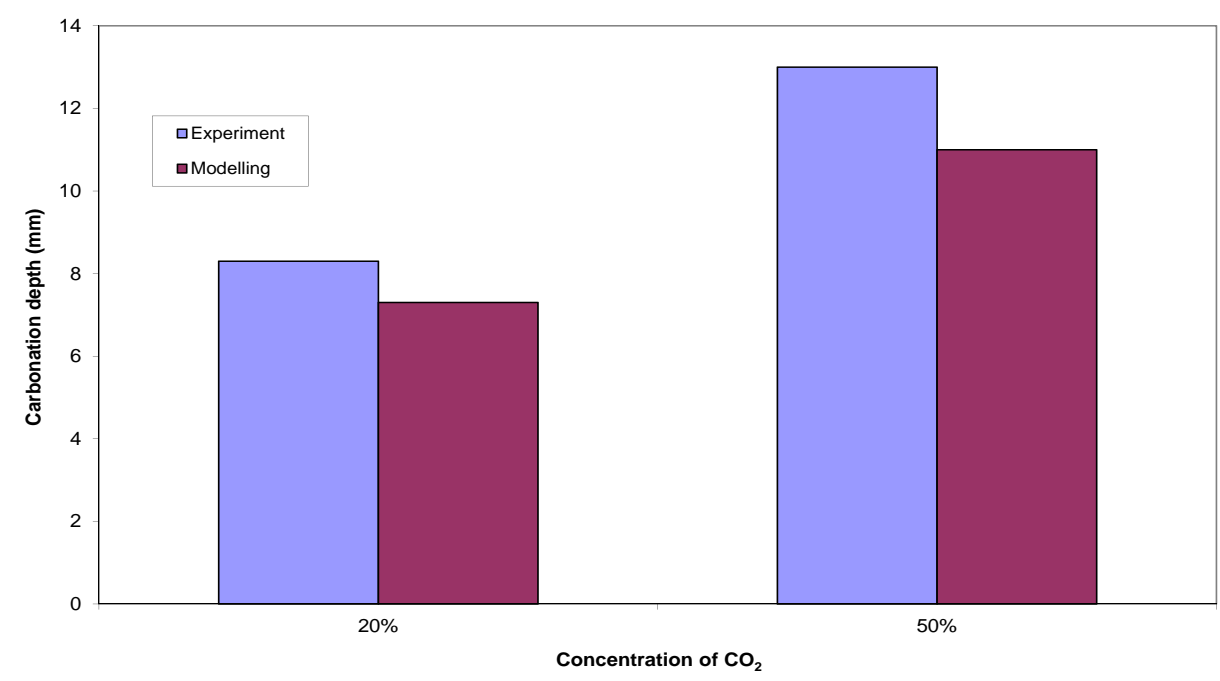

Fig. (9). Carbonation depth of cement mortar CEM II at $20^{\circ} \mathrm{C}, 65 \%$ relative humidity and $20 \%$ concentration of $\mathrm{CO}_{2}$

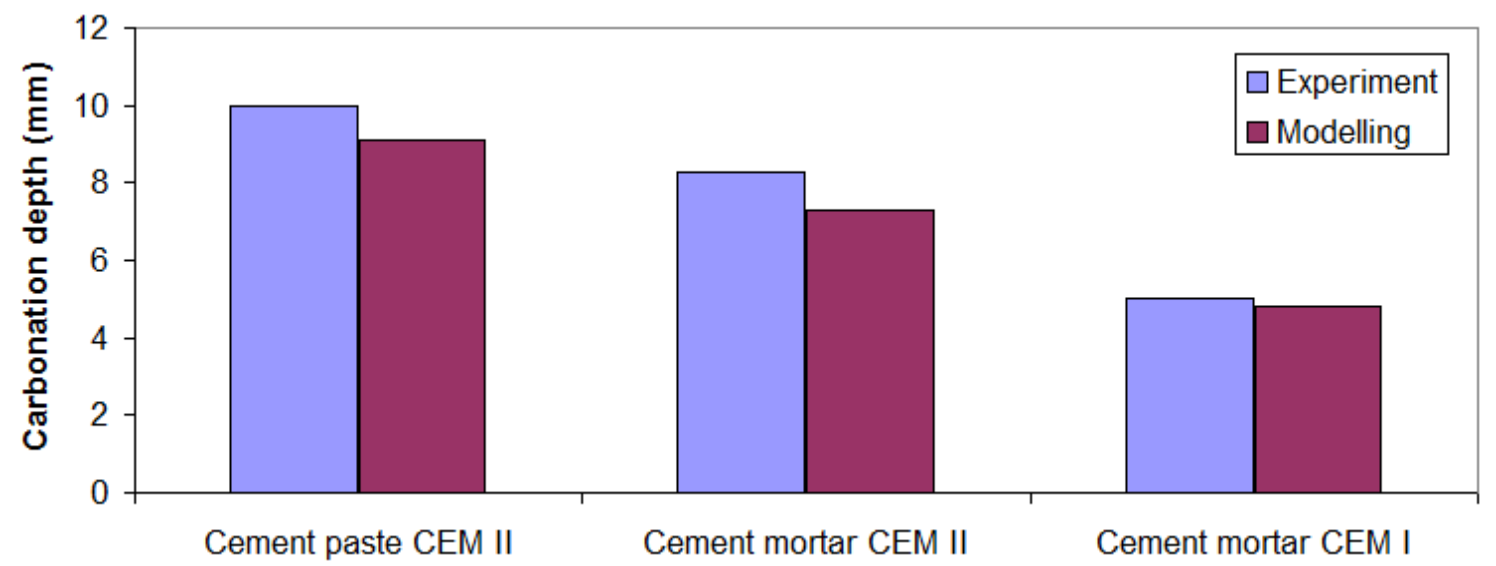

Fig. (10). Experimental and modelling results after 7 days of accelerated carbonation of cement mortar CEM II at $20^{\circ} \mathrm{C}, 65 \%$ relative humidity. 


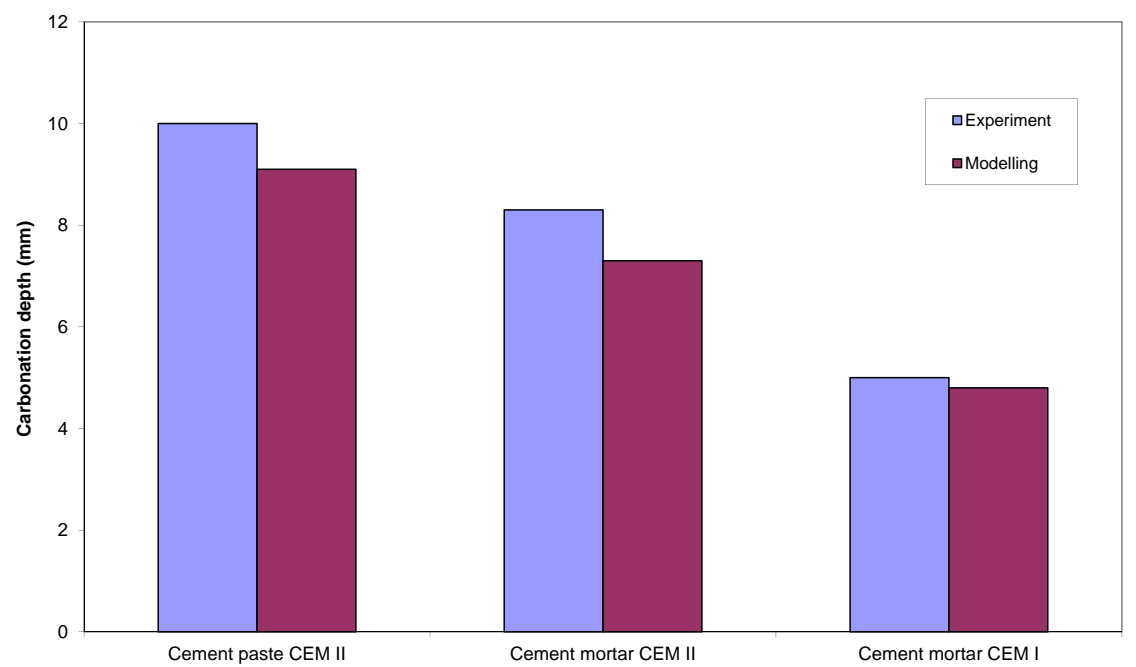

Fig. (11). Experimental and modelling results after 7 days of accelerated carbonation at $20^{\circ} \mathrm{C}, 65 \%$ relative humidity, $20 \%$ concentration of $\mathrm{CO}_{2}$.

which is adjusted from accelerated carbonation tests on cement paste and cement mortars. This test is performed by strictly controlling the initial humidity conditions of the material, the concentration of $\mathrm{CO} 2$, and the ambient relative humidity. The mass fraction of principal components of cement materials was determined using thermogravimetric analysis. The experimental results show that the main parameters which influence the most the carbonation depth are: the concentration of $\mathrm{CO} 2$, the mass fraction of $\mathrm{Ca}(\mathrm{OH}) 2$, the porosity accessible to water. Furthermore, we observe that the carbonation propagation is a unidirectional problem. The program is encoded in MATLAB by a numerical simulation using finite differences method.

For future work, it is necessary to complete the carbonation model developed by integrating the influence of cracking. According to Castel et al. $[29,30]$, the cracking of cementitious materials facilitates the penetration of $\mathrm{CO} 2$ and can drastically reduce the life of reinforced concrete structures.

In addition, it is important to remind that the model was adjusted and validated using only laboratory accelerated tests. This technique has been criticized for not being representative of the natural carbonation process and hence the application of the model for real reinforced concrete structures demands users to have critical thinking. However, the boundary and initial conditions in the natural case are much more complex and therefore less easy to take into account in the model (fluctuations in climatic conditions over time, composition of materials, curing time...). The available data are obtained over short periods and indeed not complete. For these reasons, the use of accelerated tests in the laboratory is still a common technique to simulate carbonation process in cement materials.

Finally, because of strong uncertainties in the determination of in situ input data (sustainability indicators), their randomness (due to the heterogeneous nature of concrete material) and the variability of environmental conditions (the $\mathrm{CO} 2$ concentration in the atmosphere, the relative humidity and the temperature), it will be required to address a probabilistic approach.

\section{CONFLICT OF INTEREST}

The authors confirm that this article content has no conflicts of interest.

\section{ACKNOWLEDGEMENT}

The Egyptian Government is acknowledged for the fellowship support to Ahmed Adel Ashour.

\section{REFERENCES}

[1] Y.F.Houst, and F.H.Wittmann, "Influence of porosity and water content on the diffusivity of $\mathrm{CO} 2$ and $\mathrm{O} 2$ through hydrated cement paste”, Cement Concrete Res., vol. 24, pp. 1165-1176, 1994.

[2] V.T.Ngala and C.L.Pagr, "Effects of carbonation on pore structure and diffusional properties of hydrated cement pastes", Cement Concrete Res., vol. 27, no 7, pp. 995-1007, 1997.

[3] M.Thiery, G.Villain, and G.Platret, "Effect of carbonation on density, microstructure and liquid water saturation of concrete”, In, 9th Eng. Conf. on Advances in Cement and Concrete, USA-Copper Mountain, 2003, pp. 481-490.

[4] M.Thiery, "Modélisation de la carbonatation atmosphérique des matériaux cimentaires- Prise en compte des effets cinétiques et des modifications microstructurales et hydriques", Ph.D. thesis, École nationale des ponts et chausses, Paris, 2005.

[5] V.Baroghel-Bouny, Conception des bétons pour une durée de vie donnée des ouvrages - Maîtrise de la durabilité vis-à-vis de la corrosion des armatures et de l'alcali -réaction - État de l'art et guide pour la mise en oeuvre d'une approche performantielle sur la base d'indicateurs de durabilité, Association Française du Génie Civil, 2004.

[6] A.V.Saetta, and R.V.Vitaliani. "Experimental investigation and numerical modeling of carbonation process in reinforced concrete structures - Part I: theoretical formulation”, Cement Concrete Res. vol. 34, no. 4, pp. 571-579, 2004.

[7] K.V.Balen, and D.V.Genutchen, "Modelling lime mortar carbonation”, Mater Struct, vol. 27, pp. 393-398, 1994.

[8] H.Wierig, "Long time studies on the carbonation of concrete under normal outdoor exposure”, In: RILEM Seminar Hannover, 1984, pp. 239-249.

[9] M.G. Richardson, Fundamentals of Durable Reinforced Concrete, Spon Press, London, 2002.

[10] ACI COMMITTEE 201, Guide to durable concret, ACI Manual of Concrete Practice, Farmington Hills, 2003.

[11] M. Thiery, G. Villain, S. Goyer, G. Platret, J.L. Clément, and P. Dangla, Exemple d'application d'un modèle de carbonatation in situ, BLPC, no. 270-271, pp. 29-50, 2007. 
[12] A.V.Saetta, B.A.Schrefler, and R.Vitaliani, "The carbonation of concrete and the mechanism of moisture, heat and carbon dioxide flow through porous materials”, Cement Concrete Res., vol. 23, no. 4, pp. 761-772, 1993.

[13] A.V.Saetta, B.A.Schrefler, and R.Vitaliani, "2-D model for carbonation and moisture /heat flow in porous materials”, Cement Concrete Res., vol. 25, no. 8, pp. 1703-1712, 1995.

[14] A.Steffens, D.Dinkler, and H.Ahrens, "Modeling carbonation for corrosion risk prediction of concretes structures", Cement Concrete Res., vol. 32, pp. 935-941, 2002.

[15] A.V.Saetta, and R.Vitaliani, "Experimental investigation and numerical modeling of carbonation process in reinforced concrete structures - Part II : practical applications”, Cement Concrete Res., vol. 34, no. 4, pp. 958-967, 2005.

[16] T.Ishida, and K.Maekawa, "Modeling of $\mathrm{pH}$ profile in pore water based on mass transport and chemical equilibrium theory", Concrete Library JSCE, vol. 47, no. 648, pp. 131-146, 2000.

[17] T.Saeki, H.Ohga, and S.Nagataki, "Mechanism of carbonation and prediction of carbonation process of concrete", Concrete Libr JSCE, vol. 12, no. 414, pp. 23-36, 1991.

[18] K.Maekawa, and T.Ishida, "Modeling of structural performances under coupled environmental and weather actions", Mater Struct, vol. 35, pp. 591-602, 2002.

[19] B.Bary, and A.Sellier, "Coupled moisture-carbon dioxide-calcium transfer model for carbonation of concrete", Cement Concrete Res., vol. 34, no. 10, pp. 1859 -1872, 2004.

[20] F.Adenot, Durabilité des bétons: caractérisation et modélisation des processus physiques et chimiques de dégradation du ciment, Ph.D. thesis, Université d’Orléans, 1992.

[21] B.Bary and C.Mügler, "Simplified modelling and numerical simulations of concrete carbonation in unsaturated conditions", Eur $J$. Environ. Civil Eng., vol. 9, no. 10, pp. 1049-1072, 2006.

[22] M.Thiery, P.Dangla, G.Villain, G.Platret, E.Massieu, M.Druon, and V.Baroghel-Bouny, "Modélisation de la carbonatation atmosphérique des matériaux cimentaires”, Bull Lab, pp.252-253, 2004.
[23] M.Thiery, P.Dangla and G.Villain, "Modeling and numerical simulations of concrete carbonation in accelerated and natural conditions”, In: 3rd International conference on Lifetime oriented design concepts, Bochum, 12-14 November 2007, pp.297-306.

[24] M.Thiery, P.Dangla, G.Villain and G.Platret, Modélisation du processus de carbonatation des bétons, actes des journées des Sciences de l'ingénieur du réseau des LPC, Dourdan (France), Ed. LCPC, 2003, pp. 403-408.

[25] O.B.Isgor and A.G.Razaqpur, "Finite element modeling of coupled heat transfer, moisture transport and carbonation processes in concrete structures”, Cement Concrete Compos., vol. 26, pp. 57-73, 2004.

[26] R.Miragliotta, "Modélisation des processus physicochimiques de la carbonatation des bétons préfabriqués - Prise en compte des effets de parois”, Ph.D. thesis, Université de La Rochelle, France, 2000.

[27] Association française pour la construction et pour la recherche et les essais sur les matériaux et les constructions (A.F.P.C.A.F.R. E.M), Détermination de la masse volumique apparente et de la porosité accessible à l'eau, in Durabilité des bétons - Méthodes recommandées pour la mesure des grandeurs associées à la durabilité, Ed. J.P.Ollivier, Laboratoires des Matériaux et Durabilité des Constructions, Toulouse, 1997, pp. 121-124.

[28] B.B.Véronique, Conception des bétons pour une durée de vie donnée des ouvrages, Association française de génie civil, July 2004.

[29] A.Castel, R.François, G.Arliguie, Effect of loading on carbonation penetration in reinforced concrete elements, Cement Concrete Res. vol. 29, pp. 561-565, 1991.

[30] A.Castel, G.Arliguie, T.Chaussadent, V.Baroghel-Bouny, La microfissuration superficielle a-t-elle une influence sur la profondeur de carbonatation des bétons?, Rev Française Génie Civil., vol. 5, no. 2-3, pp. 231-248, 2001.

Received: March 31, 2008

(C) Ashour et al.; Licensee Bentham Open.

This is an open access article licensed under the terms of the Creative Commons Attribution Non-Commercial License (http://creativecommons.org/licenses/ by-nc/3.0/) which permits unrestricted, non-commercial use, distribution and reproduction in any medium, provided the work is properly cited. 